\title{
Severe abdominal pain as a result of acute gastric volvulus
}

\author{
Stylianos Germanos • Stavros Gourgiotis · \\ Mahmud Saedon • Dimitrios Lapatsanis • \\ Nikolaos S. Salemis
}

Received: 23 May 2009 / Accepted: 20 October 2009/Published online: 4 February 2010

(C) Springer-Verlag London Ltd 2009

A 62-year-old male was admitted due to acute severe upper abdominal pain. His medical history included conservatively treated paraesophageal hernia. Abdominal examination revealed upper abdomen tenderness. Difficulty in passing a nasogastric tube was observed. Chest X-ray showed a diaphragmatic hernia and Gastrografin swallow demonstrated an "upside-down stomach" as a result of organoaxial gastric volvulus (Figs. 1 and 2). Gastric ischemia could not be ruled out and the decision was made for surgical intervention.

Exploratory laparotomy by midline incision was performed. The stomach was found to be ischemic albeit viable. The hernia content was reduced, the sac was excised, the crura were closed, and Nissen fundoplication was performed. The upper gastrointestinal (GI) contrast study on the fifth postoperative day confirmed complete reduction of the stomach. The patient remains free of symptoms 2 years after the operation.

Acute gastric volvulus (AGV) is a rare potentially lifethreatening condition comprising abnormal rotation of the stomach along its longitudinal (organoaxial) axis or about an axis joining the mid lesser and greater curvatures

S. Germanos · D. Lapatsanis

Second Surgical Unit, Patission General Hospital,

Athens, Greece

S. Gourgiotis $(\bowtie) \cdot$ N. S. Salemis

Second Surgical Department,

401 General Army Hospital of Athens,

41 Zakinthinou Street,

15669 Papagou, Athens, Greece

e-mail: drsgourgiotis@tiscali.co.uk

M. Saedon

Colorectal Unit, University Hospital of North Tees,

Stockton-on-Tees, UK

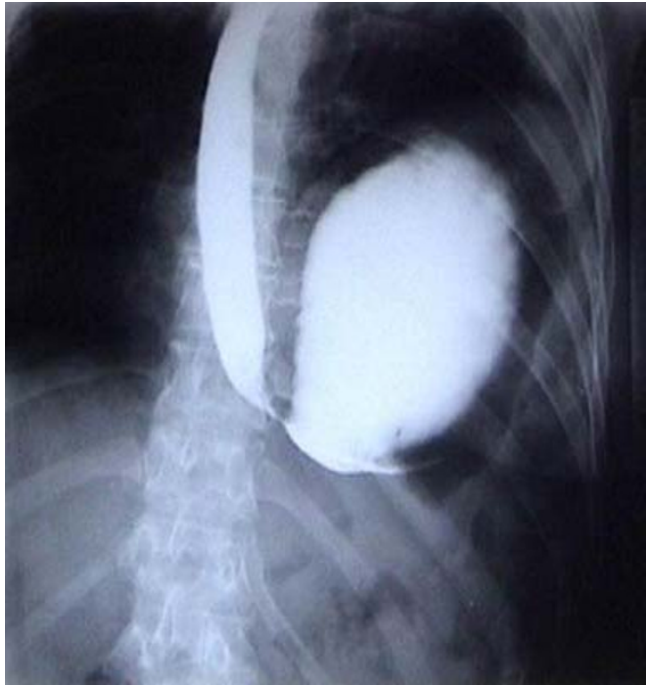

Fig. 1 Gastrografin swallow demonstrates an "upside-down stomach"

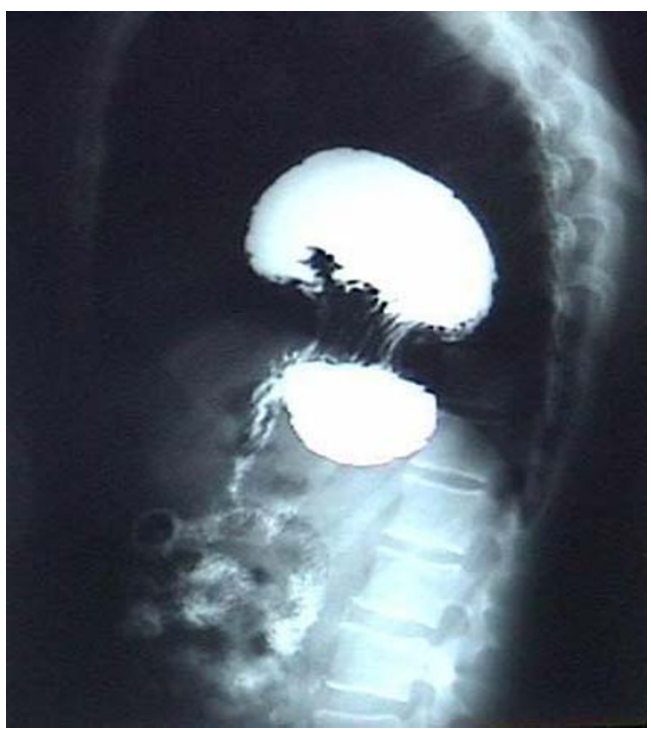

Fig. 2 Lateral view of organoaxial gastric volvulus 
(mesenteroaxial) [1]. In adults the most common cause is a diaphragmatic defect [1].

Classic symptoms of AGV are known as Borchardt's triad [2] (severe epigastric pain and distension, vomiting followed by violent nonproductive retching, and difficulty or inability to pass a nasogastric tube). If undetected, AGV can lead to ulceration, strangulation, perforation, hemorrhage, ischemia, and full-thickness necrosis [3, 4].

Diagnosis is based on contrast X-ray studies and computed tomography scan. When patients present acutely with clinical evidence of gastric compromise it is prudent to proceed immediately to exploratory surgery [5].

\section{References}

1. Gourgiotis S, Vougas V, Germanos S et al (2006) Acute gastric volvulus: diagnosis and management over 10 years. Dig Surg 23:169-172

2. Borchardt M (1904) Zur Pathologie und Therapie des Magenvolvulus. Arch Klin Chir 74:243-260

3. Schiano di Visconte M, Barbaresco S, Burelli P et al (2002) Acute abdomen due to a strangulated and perforated para-esophageal hernia (in Italian). A case report. Chir Ital 54:563-567

4. Kram M, Gorenstein L, Eisen D et al (2000) Acute esophageal necrosis associated with gastric volvulus. Gastrointest Endosc $51: 610-612$

5. Bawahab M, Mitchell P, Church N et al (2009) Management of acute paraesophageal hernia. Surg Endosc 23:255-259 